doi https://doi.org/10.31977/grirfi.v22il.2818

Recebido: 26/01/2022 | Aprovado: 27/02/2022

Received: 01/26/2022 | Approved: 02/27/2022

\title{
PROBLEMATIZAÇÃo FILANTROPA DA AÇÃo ECOLÓGICA
}

\author{
Ana Sofia de Castro Amarante e Ribeiro ${ }^{1}$ \\ Universidade do Porto (U.PORTO) \\ https://orcid.org/0000-0003-2625-3009 \\ E-mail: anasofiaamarante@gmail.com \\ Teresa Maria Castro de Almeida ${ }^{2}$ \\ Universidade do Porto (U.PORTO) \\ https://orcid.org/0000-0002-2033-0459 \\ E-mail: talmeida@fba.up.pt
}

\section{RESUMO:}

O presente artigo problematiza a dualidade existente entre os termos Terra e mundo sob o contexto da crise climática do século XXI. Nele são propostos, a partir da desconstrução de valores antropocêntricos e ecocêntricos, uma análise do paradigma filantropo/sustentável, como modo de compreender interdisciplinaridade da coexistência entre o Homem e a Natureza. Para isso, são demonstrados alguns desequilíbrios hierárquicos presentes na concessão da cultura ocidental proposta por Samuel Huntington, no imaginário ecológico das comunidades indígenas defendidas por Zoe Todd e no impacto ambiental da sociedade de consumo pela perspetiva de Patrick Curry, Richard Sylvan e David Bennett. Como resultado, é demonstrada a importância da compreensão de um equilíbrio entre o consumo e a produção, responsabilizando o antropocentrismo elitista das comunidades ocidentais como causa e solução da problemática ecológica, transversalmente ilustrada a partir do mercado e mundo da arte sob a conceção de inutilidade prática da sua existência e dado a sua contribuição para um problema de superprodução.

PalaVRaS-CHAVE: Produção; Consumo; Antropocêntrico; Sustentabilidade; Ecocêntrico.

\section{PHILANTHROPIC PROBLEMATIZATION OF ECOLOGICAL ACTION}

\begin{abstract}
:
This article discusses the existing duality between the terms Earth and world under the of the 2lst century ecological crisis. It proposes, from the deconstruction of anthropocentric and ecocentric values, an analysis of the philanthropic/sustainable paradigm, as a way of understanding the interdisciplinary nature of the possible coexistence between Man and Nature. For this, are demonstrated some hierarchical imbalances present in the concession of Western culture proposed by Samuel Huntington, in the ecological imaginary of indigenous communities defended by Zoe Todd, and in the environmental impact of consumer society from the perspective of Patrick Curry, Richard Sylvan, and David Bennett. As a result, the importance of understanding a balance between consumption and production is demonstrated, condemning the elitist anthropocentrism of western communities as the cause and solution of the ecological problem, transversally illustrated from the market and the art world under the conception of the practical uselessness of its existence and given its contribution to a problem of overproduction.
\end{abstract}

KEYWORDS: Production; Consumption; Anthropocentric; Sustainability; Ecocentric.

\footnotetext{
1 Mestre(a) em Artes Plásticas pela Universidade do Porto (U.PORTO), Porto, Portugal..

2 Doutor(a) em Estudos de Arte pela Universidade de Aveiro (UA), Aveiro, Portugal. Professor(a) da Universidade do Porto (U.PORTO), Porto, Portugal.
}

RIBEIRO, Ana Sofia de Castro Amarante e; ALMEIDA, Teresa Maria Castro de. Problematização filantropa da ação ecológica. Griot : Revista de Filosofia, Amargosa - BA, v.22 n.1, p.290-297, fevereiro, 2022. 


\section{Introdução}

Nos recentes anos tem-se assistido ao crescimento de uma tendência ecológica no filantropismo contemporâneo. Ser-se "ecológico" para além de construir uma visão utópica do mundo, acarreta o estatuto social a um nível de superioridade moral que hierarquiza as sociedades mais desenvolvidas. Contudo, conforme o termo "eco" se vai aproximando de ser uma corrente dominante, também sua perversidade tem vindo, progressivamente, a transformá-lo num termo retórico desviante, que apesar de apelar a uma visão mais verde, passa a ser controlado e manipulado pela engrenagem capitalista antropocêntrica que está na origem do problema. Esta contraposição concentra-se na origem dos fundamentos éticos ecológicos, nos quais a perspetivação entre as noções contraproducentes de mundo e Terra são esbatidos pela parcialidade tendenciosa da natureza humana.

Dessa forma, esta investigação desenvolve um dilema ético imemorial entre o antropocentrismo e o ecocentrismo, demonstrando a importância de uma consciência social ecocêntrica, como forma de transferir a valorização de um conceito fabricado de mundo, para uma Terra autossuficiente e sem uma intervenção humana negativa. Para ilustrar este paradigma, são demonstrados alguns desequilíbrios hierárquicos presentes na concessão da cultura ocidental proposta pelo cientista político Samuel Huntington (1927 - 2008, EUA), nas comunidades indígenas defendidas pela antropóloga Zoe Todd (1983 - , Canadá, Métis) e no impacto ambiental das comunidades de consumo a partir da perspetiva do Autor Patrick Curry (1951 - , Canadá), do pragmatismo do filósofo e ambientalista Richard Sylvan (1935 - 1996 , Nova Zelândia) e do político David Bennett (1970 - , Nova Zelândia).

Este enquadramento questiona, ainda, o filantropismo elitista, como solução à crise climática, através de três filosofias ecocêntricas (shallow, intermediate e deep ethics) e da conceptualização de uma culpa distribuída pelos produtores e consumidores. Assim sendo, será de seguida contextualizada a problematização da produção e do princípio de consumo, com o objetivo de exacerbar a ideia de que a humanidade deve pensar a espécie humana como parte da Natureza e não acima dela, para que possamos reabilitar e sustentar a nossa própria existência.

\section{Problematização filantropa da ação ecológica}

As recentes preocupações com o estado de conservação do planeta Terra tornam espectáveis a caracterização e a transformação de um conjunto de pré-conceitos ou códigos morais que comandam o nosso pensamento acerca da forma como vivemos e agimos no mundo e sociedade do séc. XXI. No entanto, como pode existir uma transição de uma sociedade de hiperconsumo para uma sociedade sustentável quando a transação de valores morais é bloqueada pela condição filantropa intrínseca à natureza humana.

A ética, situando-se no centro dos estudos filosóficos de carácter moral, tem vindo a contestar esta forma de viver e agir, que, no atual contexto climático, engloba distinguir e discutir sobre antropocentrismo ${ }^{3}$ e ecocentrismo ${ }^{4}$. Incessantemente, estes termos têm gerado um dilema ético, ou seja, um conflito entre o que é correto ou errado, derivado de uma matriz tendenciosa ideológica que posiciona o valor humano como núcleo egocêntrico. Contudo, para melhor compreender este dilema teremos de começar por estabelecer a sua origem e repercussões.

\footnotetext{
3 "Relacionado ou denotado à era geológica atual, vista como o período durante o qual a atividade humana tem sido uma dominante influência no clima e no meio ambiente" (STEVENSON \& LINDBERG, 2010, p. 1237)

4 "A visão ou crença de que os direitos e necessidades dos humanos não são mais importantes do que os de outros seres vivos." (STEVENSON \& LINDB, 2010, p. 3075)
} 
Primeiramente, o antropocentrismo, essencialmente, coloca o valor intrinsecamente no homem, sobrepondo a fabricada noção de mundo ao conceito de Terra. Sob uma dicotomia especista, este só se preocupa com outras formas de vida em momentos que estas fomentam ou destabilizam a sua própria existência e realidade. De forma antagónica, o ecocentrismo procura o valor intrínseco na Natureza, envolvendo todos os seres vivos e ecossistemas, e ao incluir o homem como parte dela afasta-se de ideias misantropas. Praticamente, não tendo a humanidade deixado de ser o centro das suas preocupações éticas, esta tem vindo a reconhecer o ecocentrismo como necessário para a consciencialização e antevisão do futuro. (CURRY, 2005, p.3) Porém, como pode uma sociedade afirmar que a sua própria ação é "má", quando simultaneamente cria uma ética que justifique esses mesmo atos?

Poder-se-á afirmar que na atualidade, o antropocentrismo enraizado continua a priorizar a sua ideologia na tomada de decisões cruciais, bastando olhar para o Acordo de Paris, que mesmo favorecendo a longo prazo o mundo e a Terra é negado por preferências e inclinações complexas mais lucrativas; ou ainda para o ecofeminismo ${ }^{5}$, que mesmo sendo motivado pela defesa do meio ambiente, infiltra o seu axioma feminista e expele os indispensáveis colaboradores masculinos, resultando na debilitação do próprio movimento. Notoriamente, estabelece-se um desequilíbrio hierárquico de resolução de problemas sociais, que por serem mais tangíveis de resolver ou mais simples de compreender, comprometem a credibilidade da ação ecológica.

É constado que a declinação deste paradigma está implementado no panorama sociopolítico das éticas ambientais, que tem vindo a compreender e espelhar o estabelecimento concreto etimológico do próprio movimento ecológico, dado a estarem ambos submersos neste período de revolta contra a exploração excessiva dos recursos naturais, face uma complexificação das necessidades convergentes humanas, e por isso, sendo eles provenientes de uma terminologia paradoxal, a sua essência volátil tem também sido coagida a uma metamorfose, na espectativa de obter maior coerência e relevância. (CURRY, 2005, p.4)

Particularmente, o termo "environmental" (que nos envolve), tendo adquirido uma base científica que designa os processos e sistemas biológicos que nos sustentam, é repensado, tanto pela sua subjetiva aplicação universal, que diz respeito ao proveito de cada um, como pela sua existência estar subjugada consoante a predisposição da sociedade para resolver os seus problemas. Neste sentido, o termo "ecological" (casa) ascende, aparentando resolver-se melhor, dado que, sendo a sua definição original referente ao estudo de relações entre organismos e os seus ambientes, o termo não torna a crise climática relevante apenas quando interfere com o bem-estar humano e por essa razão, quando popularizado consegue preservar a sua essência e amplificar-se de forma legítima para a política centrada na Natureza. (COLLIN, 2004, p. 69) Quando comparada à terminologia ecológica, a ética demonstra necessitar de ser mais autónoma, autossuficiente, e independente do estado e ocorrências adversas da cultura e política.

Não obstante, a ecologia não está perto de ser perfeita. É natural pensar-se a corrente ecológica como um movimento da contemporaneidade moldada pela visão ocidental e pelo colonialismo europeu, dado o recente desenvolvimento e entendimento científico do problema. No entanto, poder-se-á afirmar que a mentalidade, soluções e as atitudes ditas ecológicas sejam estritamente provenientes da cultura ocidental, como Samuel Huntington a descreve? (HUNTINGTON, 1997, 267) Talvez possamos olhar para os resíduos e fragmentos do animismo, vitalismo e do antropomorfismo da Natureza aplicados às religiões dos diferentes tempos e

\footnotetext{
5 "Há uma terceira abordagem profunda ou subjetivizada, que entende a alienação dos humanos principalmente como uma alienação da nossa dominação, civilização masculina de tudo o que é feminino, suave, sombrio sobre nós - e nos liga à Terra. A opressão da Terra surge então como uma das consequências da opressão das mulheres - e a libertação das mulheres como um passo fundamental para a libertação da natureza. Essa abordagem é geralmente rotulada de ecofeminismo" (KOHAK, 1999, p. 115)
} 
culturas (CLODD, 2012, pp. 60-84) ou até para as comunidades indígenas e a sua simbiose com a fauna e flora como modelo exemplar, que provam que a raiz do problema não é inerente ou nativa da natureza humana. (TURPIN, 2021, p. 283) Argumentar-se-á ainda que se aborda um problema contemporâneo e por esse motivo trata-se de uma questão geracional da sociedade de consumo, mas esta noção implicaria excluir países como Butão, que focam, independentemente, a sua economia em torno da sustentabilidade, tendo uma pegada negativa de emissões de carbono ou ainda excluir a atual perspetiva de artistas indígenas que promovem uma relação ancestral de entrelaçamento entre pessoas e o ambiente, e a própria indigenização ${ }^{6}$. (Ibidem, pp. 241-252)

A Métis ${ }^{7}$, antropóloga, Zoe Todd argumenta que:

Em vez de nos envolvermos com o Antropoceno como um facto teleológico que implica todos os humanos como igualmente culpados pelo atual estado socioeconômico, ecológico e político do mundo, eu argumento que devemos nos virar para a forma como os outros povos estão a descrever a nossa 'imaginação ecológica.' Para enfrentar a complexa e entrelaçada crise ambiental em que o mundo se encontra (TURPIN, 2021, p. 252)

A sua premissa recusa a culpabilidade generalizada do antropocentrismo e chama à atenção para as diferentes perspetivas, que mostram como a cultura ocidental e a sua interdependência global são responsáveis pelos problemas ambientais. Identicamente, para Patrick Curry, autor e redator-chefe do jornal, "The Ecological Citizen", a justiça climática é dependente da capacidade coletiva para restringir a mentalidade capitalista ocidental, em busca do bem comum. (CURRY, 2005, p.10) Exacerbando a ideia de que a epistemologia das comunidades indígenas parece ter mais lógica moral que uma sociedade mais desenvolvida tecnologicamente e cientificamente.

O antropocentrismo, perspetivado num olhar ocidental, passa a ser então o fator mais determinante da dinâmica da ação ecológica, acabando por fazer o cambio direto de significados como a exploração, o consumismo e com o dever de subordinação da ganância a valores éticos mais verdes ${ }^{8}$. Enquanto, o ecocentrismo é determinado como uma característica de nobre humanidade e altruísmo, que colide com o antropocentrismo através de regras que orientam a liberdade. (KOHAK, 1999, p. 60)

Num olhar aproximado, Richard Sylvan e David Bennett discutem sobre uma estrutura que calcula concretamente o impacto ambiental das dinâmicas implícitas numa ideologia antropocêntrica. Em específico, $\mathrm{I}=\mathrm{P} \times \mathrm{L} \times \mathrm{T}$, onde nomeadamente $\mathrm{P}$ significa a dimensão populacional (número de pessoas), L o estilo de vida (afluência ou consumo, o uso per capita de recursos) e T a tecnologia (o efeito per capita de tecnologias que consomem mais ou menos energia e que poluem), aparenta ser a solução mais neutra ao problema. (BENNETT, 1994, pp. 46-50) Contudo, a complexidade e fragilidade ética intercalada, impede que estes fatores sejam analisados com imparcialidade. Por exemplo, havendo uma sobrepopulação na China, devemos

\footnotetext{
6 “demanda dos povos indígenas pelo seu próprio espaço na ordem cultural do mundo. Em vez de uma recusa das comodidades e relações do sistema-mundo, isso significa mais frequentemente o que o Enga cantou, um desejo de os indigenizar. O projeto é a indigenização da modernidade."] (SAHLINS, 1999, p.10)

${ }^{7}$ Termo que define os povos indígenas no Canadá e em partes dos Estados Unidos, que são reconhecidos como os únicos com ascendência indígena e europeia: "Esta trajetória evolutiva do termo métis é discernível no comentário dos Oblatos sobre os habitantes indígenas de Île-à-la-Crosse. Desde a fundação de Saint-Jean-Baptiste em 1846, os Oblatos estavam, sem dúvida, conscientes de um grande contingente de sangue mestiço na comunidade, dada a difusão de sobrenomes europeus e o papel histórico da Île-à-la-Crosse como uma zona de contato entre grupos etnolinguísticos distintos. No entanto, eles não atribuíram nenhum significado intrínseco à mistura de sangue, referindo-se antes aos membros da comunidade, coletivamente, como des sauvages, com base nas considerações linguísticas e religiosas." (FORAN, 2017, p.147)

8 "compromisso em conter ou reduzir o impacto ambiental dos humanos na Terra ou em regiões dela." (BENNETT \& SYLVAN, 1994, p. 22)
} 
limitar o número de filhos por família, quando existe um excesso de consumo de recursos e de tecnologia poluente nos EUA? Decisões às quais o antropocentrismo tem dificuldades em responder e que o ecocentrismo consegue simplificar, através da comparação analítica, mas que no final não se traduzem num acordo universal, dada à natureza pessoal e subjetiva do ser humano, e dos seus fenómenos sociais. É ponderável, que ambas as conceções têm de chegar a acordo e comprometer certos valores, de maneira a resolver mais facilmente e rapidamente a crise climática.

Patrick Curry ilustra esta discussão, assegurando que:

\begin{abstract}
Não haveria necessidade de escolher entre a injustiça social e o suicídio ecológico se a minoria rica reduzisse seu consumo - e apenas a um nível que ainda permitiria um estilo de vida 'europeu' razoavelmente confortável (numa extremidade modesta da escala) enquanto a maioria aumenta o seu o suficiente para permitir o mesmo. (Nem seria necessário que a maioria vivesse com baixos níveis de consumo se o número total populacional fosse menor). (CURRY, 2005, pp.15-16)
\end{abstract}

Colocando assim em questão a permanência de um antropocentrismo elitista, que ostenta não conseguir retirar o seu juízo filantrópico de decisões mais austeras, impostas pela ecologia, em prol do benefício utilitário mundial, ainda que estas sejam significantemente menores quando comparados às consequências da crise climática. Todavia, a tomada de consciência desta norma, não significa que seja impossível uma transfiguração da mentalidade capitalista. De forma gradual tem-se assistido a um crescimento de éticas que procuram inserir-se no âmbito ecocêntrico, isto é, referente à forma como se posiciona o valor no H/homem comparativamente à Natureza. Das quais, se podem associar a três filosofias ${ }^{9}$ distintas: (1) light green ou shallow ethics que tenta salvar a Natureza em favor da sobrevivência da humanidade; (2) mid-green ou intermediate ethics, que vê tanto valor no ser humano como na Natureza, colocando-o apenas como superior às outras espécies; (3) dark green ou deep ethics, puramente ecocêntrica assume o valor na Natureza, cujo homem faz parte. (CURRY, 2005, pp. 47-99). Prova disso são as obras escritas "Lifeboat Ethic" de Garrett Hardin, "The Land Ethic" de Aldo Leopold, a "Gaia Theory" de James Lovelock e Lynn Margulis, a "Deep Ecology" inspirado no trabalho de Arne Naess, a "Deep Green Theory" de Richard Sylvan e "The Earth Manifesto" de Ted Mosquin e Stan Rowe, que marcam, até hoje, uma grande influência no modo como pensamos a humanidade/mundo e a Natureza/Terra. (KOHAK, 1999, pp. X-XI)

Por fim, esta manifestação em direção a ideologias mais verdes, não surge sem os seus obstáculos, pelo que, ao oferecer uma sensação de pertença, de comunidade e coletivismo sucedese uma validação personalizada do individuo social, por via de correlação a qualquer uma destas filosofias ou éticas, sem que este a aplique em si mesmo ou modifique os seus hábitos. O que acaba por tornar mais fácil retirar qualquer responsabilidade das mãos da população e incitar antes a culpabilização direta dos governos e indústria. Por outras palavras, a existência de um raciocínio ideológico, que dá a hipótese de rotular determinada entidade ou indivíduo, não se assemelha ou compara a mostrar exemplos ou à formulação de modos/regras de praticar essa mesma ideologia. Contudo, não sendo completamente afastada da realidade, este ponto de vista, segundo Milton e Rose Friedman, deve entender a poluição como algo comum a todos aqueles que lucrem dela,

\footnotetext{
${ }^{9}$ Cunhadas e desenvolvidas pelo filósofo e ecologista norueguês Arne Næss: “Assim as éticas ambientais, nas suas variadas formas, shallow e deep, utilitárias ou deontológicas, são todas e cada uma ética; algumas delas têm como objetivo fornecer tanto uma teoria da moralidade, como uma moralidade defendida, características da própria prática e, portanto, não apenas vincular a prática (pela qual as pessoas vivem) e a teoria, mas também eliminar possíveis ambiguidades." (BENNETT \& SYLVAN, 1994, p. 3)
} 
incluindo consumidores, "eles criam, por assim dizer, uma exigência de poluição." (FRIEDMAN, 1980, pp. 285-286). Cabendo assim, a cada um estabelecer uma ecosofia ${ }^{10}$ ou consciência moral para com o seu próprio impacto ambiental.

Nesta lógica, quando analisado o princípio de produção e consumo sob o panorama elitista, entendem-se que ambas as posições éticas do mundo e Terra podem coexistir através de uma balança moral, cujo filantropismo deve-se submeter à perda de valores supérfluos dispensais de ostentação e sumptuosidade, e o ativismo ecológico deve compreender, auxiliando a contrariedade a ver, por outros primas, a solução a esta crise. Querendo isto dizer, por exemplo, repensar a arte como mercado de consumo dispensável à sobrevivência humana, pode não ser a resposta, pelas razões anteriormente referidas, mas antes uma reestruturação honesta das matérias e formas como se produzem e consomem objetos de arte sob condições e regulamentações sustentáveis, desde o produtor a um consumidor emancipado que escolhe o que valorizar, podem ser a solução a este contratempo ético.

Assim, a ética ecocêntrica representa um acordo entre os valores ecológicos ativistas e as necessidades filantropas antropocêntricas. Esta não insurge forçosamente na sociedade sob princípios de radicalização extrema da realidade, pois sabe os seus limites reacionários, mas antes compromete os seus valores ajudando e mostrando alternativas à realidade, que propulsionam, progressivamente, um futuro mais verde.

\section{Conclusão}

A atual crise climática põe em causa a validade de se continuar a produzir e consumir sob princípios antropocêntricos capitalistas. A transição para uma perspetiva ecocêntrica do mundo representa o desejo e a necessidade de mudança, ganhando presença no termo Terra. Este relaciona-se melhor com o conceito de coexistência entre o Homem e Natureza, negando a noção fabricada e restabelecendo a alienação da Natureza como forma de ver o futuro da humanidade, através da ética.

Este imperativo moral, revela ser a chave para a reformulação do movimento ecológico, dado a este estar fragilizado pela conduta antropocêntrica. Dessa forma, no decorrer do artigo compreendemos que a ética ecológica deve ser autónoma, autossuficiente e independente do estado das ocorrências adversas dos fenómenos sociais, económicos e políticos da sociedade, devido a esta ser dependente de uma mentalidade antropocêntrica ocidentalizada, que escolhe a exploração e o consumo, por via de uma persuasão filantropa, acima de um ecocentrismo essencial, mais altruísta, restringido e disciplinado.

Após uma análise comportamental, é notado que ambas as perspetivas devem chegar a um acordo para resolver a crise climática. Estando respetivamente a produção e o consumo no centro do problema e não sendo impossível transfigurar esta mentalidade através de ecosofias e da redução de um consumo elitista, é dado como caso de estudo o papel que a arte deve ocupar, uma vez que, sendo esta entendida como hiperprodutiva num contexto prático de inutilidade dispensável elitista, a sua adaptação a meios de criação mais sustentáveis, representam a solução mais viável ao contratempo filantropo num mundo, ainda, antropocêntrico, mas como um desejo ecocêntrico.

\footnotetext{
10 “Assim, uma ecosofia é uma visão de mundo filosófica ou um sistema inspirado pelas nossas condições de vida na ecosfera. Tanto Næss quanto Guattari sugerem que uma ecosofia é mais do que um mero sistema abstrato de pensamento. Na verdade, ele exige uma mudança radical nas visões e crenças, desafiando modelos antropocêntricos há muito estabelecidos que governam a dicotomia natureza/cultura, a noção de domínio e propriedade sobre outras espécies e as premissas finais da vida" (LEVESQUE, 2016, p. 512)
} 
Em suma, a ética ecocêntrica proporciona, aos olhos desta investigação, os meios para transitar a valorização da Natureza e repensar o futuro do planeta. Contudo, deve ser exercida sobre o sentido de evolução progressiva e não de insurgência coagida na sociedade antropocêntrica, devido, ainda, estarmos embebidos num filantropismo incapaz de se negar a si próprio em prol de algo que parece inatingível. 


\section{Referências}

BARTHEL-BOUCHIER, D. Sacha Kagan, Art and Sustainability: Connecting Patterns for a Culture of Complexity. International Sociology, 2012. 27(5), 683-686. https://doi.org/10.1177/0268580912452375

BENNETT, D., \& SYLVAN, R. The Greening of Ethics. Tucson, USA: University of Arizona Press, 1994.

BENNETT, J. Vibrant Matter: A Political Ecology of Things (John Hope Franklin Center Book). Duke University Press Books, 2010.

CURRY, P. Ecological Ethics: An Introduction (1 ${ }^{\circ}$ ed.). Polity Press, 2005.

CLODD, E. Animism, the Seed of Religion. Amsterdam, Netherlands: Adfo Books, 2012.

COLLIN, P. Dictionary of Environment and Ecology: Over 7,000 terms clearly defined (Bloomsbury Reference) ( $5^{\circ}$ ed.). A\&C Black, 2004.

DELEUZE, G., \& GUATTARI, F. Anti-Oedipus: Capitalism and Schizophrenia. University of Minnesota Press, 1983.

FRIEDMAN, R. M. Liberdade para Escolher, Publicações europa-américa, 1980.

FORAN, T. P. Defining Métis: Catholic Missionaries and the Idea of Civilization in Northwestern Saskatchewan, 1845-1898 ( $1^{\circ}$ ed.). University of Manitoba Press, 2017.

HUNTINgTON, S. P. O Choque de Civilizações e a Recomposição da Ordem Mundial (5 ed.). Objetiva,1997.

KOHAK, E. The Green Halo: A Bird's-Eye View of Ecological Ethics. Chicago and La Salle, Illinois: Open Court, 1999.

LEVESQUE, S. Two versions of ecosophy: Arne Noess, Félix Guattari, and their connection with semiotics. Sign Systems Studies, 2016, 44(4), 511-541. https://doi.org/10.12697/sss.2016.44.4.03

SAHLINS, M. What is Anthropological Enlightenment? Some Lessons of the Twentieth Century. Annual Review of Anthropology, 1999, 28(1), i-xxiii. https://doi.org/10.1146/annurev.anthro.28.1.0

STEVEnSON, A., \& LINDBERG, C. A. New Oxford American Dictionary 3rd Edition ( $3^{\circ}$ ed.). Oxford University Press, 2010.

TOBGAY, T. This country isn't just carbon neutral - it's carbon negative. YouTube, 2016. Acedido em https://www.youtube.com/watch?v=7Lc_dlVrg5M

TURPIN, H. D. E. Art in the Anthropocene: Encounters Among Aesthetics, Politics, Environments and Epistemologies (Critical Climate Change). Open London: Humanities Press, 2015.

WORLD COMMISSION ON ENVIRONMENT AND DEVELOPMENT. Our Common Future (Oxford Paperbacks ed.) (1 ${ }^{\circ}$ ed.),1987.

Contribuição dos(as) autores(as) / Author's Contributions:: Ana Sofia de Castro Amarante e Ribeiro e Teresa Maria Castro de Almeida participaram da discussão, redação e revisão do artigo. Ambos(as) aceitaram e aprovaram a versão final do texto.

Autor(a) para correspondência / Corresponding author: Ana Sofia de Castro Amarante e Ribeiro. anasofiaamarante@gmail.com 